\title{
Rethinking Macroeconomy and Central Banking in the New Normal ${ }^{1}$
}

\author{
Perry Warjiyo ${ }^{2}$
}

Ladies and Gentlemen, welcome to the 14th Bulletin of Monetary Economics and Banking (BMEB) International Conference and Call for Papers, 27 August 2020. I am extremely proud to see the advancement of BMEB over a very short period of time to become one of the most respectable journals in Indonesia and the region. Not only that, BEMB has already gone beyond the region, competing and creating a unique space for policy-based research amongst journals globally. And with that, I am delighted to deliver my keynote address at this 14th BMEB International Conference.

I recall last year, when delivering my keynote address at the 13th BMEB International Conference and Call for Papers in the beautiful island of Bali, I pointed out the phenomenon of "Diminishing Globalization and Rising Digitalization". On that occasion, I referred to the diminishing globalization in light of the intensified trade war between the US and China, and rising digitalization among others for greater use of robotics, artificial intelligent, and machine learning.

\section{Acceleration of diminishing globalization and rising digitalization}

Here we are, amidst the COVID-19 pandemic. We all are witnessing an even faster acceleration of diminishing globalization and rising digitalization. We see the increasing inward-trade policies in many countries, not only for the survival of domestic economies from the COVID-19 pandemic, but also the signs of diminishing international trade and vulnerability of international finance. On international trade, for example, the COVID-19 pandemic has exposed the vulnerability of the global economy that relies excessively on a centralized global supply chain in one major country, China. The COVID-19 pandemic which began in China and spread globally resulted in lockdowns and restrictions on the mobility of people and goods. This caused major disruptions to global trade and economic growth. The global supply chain has been severely disrupted, and the global economy has entered a recessionary phase. The COVID-19 pandemic reflects the importance and the need for diversification of the global supply chain into a multipolar international trade supply chain.

In the international finance arena, with the spread of the COVID-19 pandemic came panic in the global financial market-this became a feature of the market in March and April 2020. The immediate response of investors globally was to withdraw their investments in financial assets, regardless of their return and risk

\footnotetext{
1 Keynote Address at the $14^{\text {th }}$ Bulletin of Monetary Economics and Banking (BMEB) International Conference and Call for Papers, Jakarta, August 27, 2020

2 Governor of Bank Indonesia, the Central Bank of the Republic of Indonesia
} 
profile, and convert them into cash, i.e. in the US dollar. The COVID-19 pandemic accentuates the vulnerability of the global financial system that relies heavily on the US dollar. The pandemic made the global financial system more unstable and riskier. Furthermore, dollar liquidity shortage has triggered large capital outflows from emerging markets, putting pressure on the exchange rates, foreign exchange reserves, and domestic monetary and financial system stability.

At the same time, rising digitalization accelerated with the COVID-19 pandemic. We are not only talking about robotics, greater use of artificial intelligent and machine learning, but digitalization in every aspects of our life. Digitalization has accelerated in the economy and in finance-related activities as well as in the way we function, particularly with respect to health, education, and learning. Even now we are using digitalization in this conference. Digitalization also gives more accessible global knowledge that we can use. Digitalization also leads the way for acceleration of Micro-Small-Medium Enterprises (MSMEs) to be one of the engines of economic growth in the new normal. However, there is also the question of who owns the data because data are like "new oil" so that a country can use the benefits of data for domestic economic activity and growth, as well as cyber security.

Ladies and gentlemen, now we are seeing even faster diminishing globalization and much faster rising digitalization. With this background, this is the best time to have reflections, particularly on how the macroeconomy and central banks needs to rethink and adjust to these phenomena. So, the theme of this conference is a reflection on how we think about economic theory, reflection about macroeconomic policy -nationally and globally - a reflection also on the ways in which we do business and conduct economic activities. And beyond that, from the central bank perspective, a reflection of how central banks must adapt and adopt a new way of making and implementing the policy of central banks in the era of digitalization. Let me offer you my personal reflections on these two aspects. The first part of my keynote will cover reflections on the national economic policy, and then the second part will be on the central bank in the digital era.

\section{Macroeconomic Policy in the New Normal}

Let me start with my reflections on the national economic policy. Let me offer you the following five key points on macroeconomic policy and strategy at the back of faster acceleration of diminishing globalization and rising digitalization.

First, we must rethink, on new sources of economic growth. This effort should be global. Yes, we need to continue engaging with international trade and finance, as they bring about positive impacts to the domestic economy. But new sources of domestic growth are becoming more important as they form the basis of national economic resilience against shocks that originate globally such as the COVID-19 pandemic. The new sources of domestic economic growth depend of course on the endowment of each country. For us in Indonesia, for example, as for not relying too much on exporting our natural resource, we need to develop downstream industries for processing these national resources into more value added products for both exports and domestic markets. We do down-streaming for palm oil, mining, and other natural resources. For other new sources of domestic 
growth, we need also to accelerate our tourism, infrastructure, and MSMEs. New sources of economic growth and diversification of the domestic economic source of growth are the most important aspects of diminishing globalization and rising digitalization. For that purpose, we need to embrace much faster structural reforms in the real sector, in the industry, in agriculture, in maritime, in tourism, and in every other aspect of economy. In Indonesia, these reform agenda is one of the high priority policies under the direct leadership of President Joko Widodo.

Second, we need to develop the domestic supply chain. Globally, of course, we will continue engaging with multipolar global supply chains, not only to the one centralized global supply chain to diversify export promotion. But domestically, we need to develop domestic supply chains to interlink and integrate one domestic economic activity/zone with another to support our national economy. We need to develop domestic and national centres of the sources of economic growth that are interconnected, become domestic supply chains, and engage with multipolar global chains. This strategy will accelerate growth, export promotion, and import substitution. In Indonesia, the aim is for Java to become an industrial zone while other regions will be sources of inputs because of their rich national resources. In this aspect, infrastructure, domestic connectivity -physical as well as telecommunication- are especially important to support this domestic supply chain. To support our economic transformation, we need to understand how we process our national resources to be used by industry. Within the industry, we need to process to medium and high value-added products, both for domestic consumption and exports. Equally important is how these industries will be supported by services, both trade services and financial services.

Third, we need to continue to improve our business and investment friendly environments. The reforms in these areas are extremely important because most developing countries cannot rely only on domestic sources of savings. We need foreign investment to fill the domestic saving-investment gap to develop the domestic economy in order to achieve higher growth. In this aspect, Indonesia is in the process of finalizing the Omnibus law (UU Cipta Kerja) which aims to streamline investment and business processes and develop and link economic zones throughout the country into national supply chains through infrastructure connectivity. These bold investment reforms overall aim at increasing investments from domestic and foreign sources to finance our national economic strategy towards "Indonesia Maju" as a high-income-country.

Fourth, is the phenomena of digitalization. In most of emerging countries, digitalization of economic and financial systems, especially in the MSMEs, aims at supporting higher economic growth that is also financially and economically inclusive. Indonesia has about 67.4 million units of MSMEs that support about $55.5 \%$ of GDP and absorb more than $97 \%$ of the labour force. So far, the strategy for MSMEs development tends to rely on financial support from both the government and the financial sector. We need to reshape the strategy towards enhancing cooperation through grouping and zoning these MSMEs and providing them with technical assistance with respect to entrepreneurship, production, finance, and marketing. Under the new approach, digitalization of MSMEs is being accelerated through closer synergy by the government, Bank Indonesia, and other agencies, working together with the banking sector and related associations. Digitalization 
of MSMEs will be faster through the use of e-commerce, merchant, FinTech, open banking and start-ups. Thus, digitalization of MSMEs is becoming the new source and strength of economic growth. It is contributing to inclusive national economic growth, one that is modernized and integrated into domestic and global supply chains. Digitalization of MSMEs is also an important aspect on our rethinking of macroeconomic theory and policy, as Schumacher's school of thought, Small is Beautiful. ${ }^{3}$

My last reflection is about rethinking the national economic policy mix. Our macroeconomic policy needs to encompass and provide solutions on how best we coordinate to synergize our policies on structural reforms in the real sector to develop new sources of growth, interlink domestic supply chains through infrastructure connectivity, streamline business and investment processes with fiscal policy to support those strategies through tax incentives, as well as reorientation of government expenditures. Coordination between fiscal and monetary policies is also important for ensuring macroeconomic stability as well as ensuring both policy stances are supportive of economic growth. Structural reforms must also encompass the financial sector, aimed at deepening the banking and financial market for mobilizing savings and financing the national growth strategy. Closer coordination and synergy of these national economic policies continue to be strengthened between government, Bank Indonesia, and other agencies with respect to the role of authority and independence of each institution.

\section{Central Banking in the Digital Era}

Let me now turn to the second part of my keynote address, which is on my reflections on the central bank in the digital era. Central banks need to adapt and adopt the new way of fulfilling the central bank mandate: such as, what are the objectives, and how to conduct monetary policy, macroprudential, as well as payments system? How central bank must reform in this rising digitalization in response to acceleration of digital economy and finance? Let me offer the following five reflections on these issues.

First, I am still a true believer that central bank policy mix is one of the key frameworks that need to be adopted by central banks, especially in the emerging market economies. In the past, Bank Indonesia adopted the inflation targeting framework (ITF). But after the Global Financial Crisis of 2008/09, the central bank could not only focus on price stability; the bank must also support financial system stability. For this reason, for Bank Indonesia, as described in my book (Warjio and Juhro, 2019) on the central bank policy mix, the objective is not only to achieve price stability but also support financial system stability. ${ }^{4}$ With this dual mandate, the central bank policy is a mix of monetary and macroprudential policies together with capital flows management as well as exchange rate stabilization. We described in detail in our book the underpinning theory, policy practice, as well as empirical

3 Schumacher, E.F., Small is Beautiful: A Study of Economics as If People Matters, Blond \& Briggs Publisher, 1973.

4 Warjiyo, Perry and Juhro, Solikin M., Central Bank Policy: Theory and Practice, Emerald Publishing Limited, 2019. 
studies that support the central bank policy mix. We also just published a new book recently that provides further empirical studies and policy practices, entitled "Central Bank Policy Mix: Issues, Challenges, and Policy Responses". ${ }^{5}$ The book integrates key lectures, country experiences, and case studies from the five year conferences organized by the Bank Indonesia Institute.

Second, we need to place the central bank policy mix as a part of national policy mix through policy coordination. In other words, the independence of the central bank needs to be maintained but within the interdependence of national economic policy, while respecting the authority of each of the institution's mandate and policy. As I mentioned before, the national economic policy encompasses coordination and synergy among structural reforms, fiscal policy, as well as central bank, financial market, and other key national economic policies. The coordination in the national economic policy aims, within the principle of interdependent of independence of each policy, to be effective in achieving economic goals, higher economic growth with macroeconomic stability. Just like in academia, we are working through simultaneous equations, where one equation needs to be interlinked with the other equations, thus simultaneously solving the problem and advancing national economy. Achieving price stability will be more effective if monetary policy is supported by structural and fiscal policies that enhance aggregate supply and manage aggregate demand. Likewise, higher economic growth with structural reforms and fiscal policy to expand aggregate supply will be more sustainable without incurring pressures on inflation and current account deficit if monetary policy is able to manage aggregate demand.

Third, the central bank must play a greater role in accelerating financial deepening. In many emerging market economies, the financial resilience of a country and the effectiveness of policy transmission very much depends on how deep domestic financial market is. Capital flows volatility is not only driven by the global financial market condition but is also rooted in the depth of the domestic financial market. Likewise, the liquid and efficient domestic financial market will enhance the effectiveness of monetary quantitative easing to the banking and financial sector as well as to the real sector. When I refer to the deepening of financial market, I am not only talking about introducing more financial instruments, but also enhancing market price mechanism and market conducts. Beyond that, it also encompasses building domestic financial and payment market infrastructures, especially developing trading platform, central counter party (CCP) clearing house, integrating money market and capital market, as well as domestic retail investor. Those payments and financial market infrastructures are especially important to be integrated, interconnected so that flourishing more liquid, efficient price mechanism, and large transactions in the domestic financial market. Deep domestic financial market will not only able to mobilize saving to finance domestic economy, but will also make it attractive to foreign and domestic investors. It will also make the market resilient to volatile capital flows.

The fourth issue is the digitalization of the payment systems. Central banks in the digital era must ensure that digital currency authority is within the central

5 Warjiyo, Perry and Juhro, Solikin M, (editors), Central Bank Policy Mix: Issues, Challenges, and Policy Responses - Handbook of Central Banking Studies, Bank Indonesia Institute, 2020. 
bank. We cannot relinquish digital currency to the private sector. Digital money is the same thing as coin money, fiat money, or paper money. They play a pivotal role as a medium of payments and money supply process so that forms the basis for the conduct of monetary and macroprudential policies. The authority of digital currency must be reliable and trustworthy and must be the sole authority of the central bank. Digital payments system also aims to integrate domestic digital economy and finance to form end-to-end money supply process so that it forms the basis for monetary and macroprudential policies. How digital currency can be used in MSMEs, in trade, in corporate, linking to e-commerce, linking to the FinTech, how to foster digital banking, open banking, how to develop fast payment, and how to integrate those into the central bank money are key issues.

Last year, in May 2019, we issued the Blueprint of Indonesia Payment System $2025 .^{6}$ The blueprint, which articulates our vision in developing payment system, contains five key aspects, namely, integration of the domestic digital economy and finance, promoting and accelerating open banking, interlink between digital banking and FinTech, promoting start-ups and developing payments system infrastructure, and cross-border digital payments system consistent with the objective of national interests. We are moving extremely fast towards digitalization of our payments system. In this process, we are working together with the banking industry, FinTech, and others association.

My final perspective is that central banks need to embark on total transformation, particularly in the areas of policy, institutions, human resources, and digital progress, to move towards Central Bank 4.0. Policy transformation is not only about strengthening the policy mix, but it is also about developing the integrated policy framework of monetary and macroprudential policies, supported by a digitalized payments system. Policy transformation of central banks is to respond to the challenges arising from diminishing globalization and rising digitalization. Institutional transformation is important to strengthen the governance and decision-making processes, and to digitalize the business process for both policy making and institutions. Human resource transformation is particularly important in order to continue to enhance the capacity and capability of central banks in carrying their mandates in a more complex environment of diminishing globalization and rising digitalization. Thus, it must encompass the capacity and capability in central banking but also in digital economy and finance. I spend a lot of time on the human resource transformation. This is where Bank Indonesia Institute plays a key role in delivering modern and advanced learning and research that makes a difference to policy. Digital transformation is of utmost importance in moving central banking in the digital era. This underpins our revised vision recently, to be the first and best digital central bank in contributing to the national economy and the best among emerging markets. We embark upon total transformation of digitalization: developing digitalized policy and institution business processes, enhancing data hub and omni-repository, building omniexperience technology infrastructures, and strengthening human resource digital capability and mind-set. In short, we embark upon these five transformations to achieve our new vision of Bank Indonesia to be the leading digital central bank.

6 Bank Indonesia, Indonesia's Payments System Blueprint 2025, http://www.bi.go.id., 2019. 
These conclude two parts of my reflections. My contemplation as a Governor of Bank Indonesia about macroeconomic policy and the role of the central bank in this extremely fast acceleration of diminishing globalization and rising digitalization. These are complex issues at the back of the COVID-19 pandemic. I am proud to be supported by my fellow Board of Governors, my brilliant senior officials, economists, and most of all my $60 \%$ of innovative and energetic millennials working with Bank Indonesia. We committed for total transformation, to implement our new formulated Strategic Business Plan 2020-2025 towards our vision to become the leading digital central bank that contributes to the progress of the national economy and to be the best central bank amongst emerging markets. With these reflections, and with the blessing of God Almighty, I herewith officially declare the $14^{\text {th }}$ Bulletin of Monetary Economic and Banking International Conference and Call for Papers 2020 open. May God Almighty always guide us on the right path, provide insights and strength for enhancing the role of the central bank in fostering our economy for the benefit of humanity and society. 
This page is intentionally left blank 